\title{
ELES NÃO USAM BLACK-TIE E RASGA CORAÇÃO: UMA LEITURA A PARTIR DA ÉTICA
}

ELES NÃO USAM BLACK-TIE AND RASGA CORAÇÃO: AN ETHICAL INTERPRETATION

\author{
Marcelo Fernando de Lima ${ }^{1}$
}

RESUMO: O objetivo deste trabalho é a análise das peças teatrais Eles não usam Black-Tie, de Gianfrancesco Guarnieri, e Rasga Coração, de Oduvaldo Vianna Filho, a partir de uma abordagem temática que privilegia a discussão ética. O artigo busca mostrar o contexto social em que as peças foram escritas e encenadas e procura resgatar seus possíveis significados políticos.

PALAVRAS-CHAVE: Teatro. História. Política. Ética. Arte engajada.

ABSTRACT: The aim of this paper is to analyze the plays Eles não usam Black-Tie, written by Giafrancesco Guarnieri, and Rasga Coração, by Oduvaldo Vianna Filho, by focusing on a thematic outlook which stresses the ethical discussion. This text aims to reveal the social context in which those plays were written and performed, besides it retrieves its political meanings.

KEYWORDS: Theater. History. Politics. Ethics. Engaged art.

\section{Introdução}

Eles não usam Black-Tie, de Gianfrancesco Guarnieri, marcou o início de uma nova fase da dramaturgia brasileira, no final da década de 1950, centrada no engajamento político (PRADO, 1993, p. 109). A peça centra-se numa família operária, de um morro carioca, durante uma greve. Foi a primeira vez que essa temática apareceu na dramaturgia brasileira, mostrando, por meio de um tratamento direto, a necessidade de conscientização política e o engajamento na luta de classes. É também uma obra sobre o conflito entre pai e filho em torno de uma postura ética. Otávio, líder de esquerda e organizador de greves, sente-se na obrigação de expulsar de casa o filho Tião, um jovem individualista, furagreve, que se preocupa em ascender profissionalmente e sair da favela. A maior tensão da peça se dá na cena em que o pai renega o filho pelo bem de um endurecimento ético necessário àquele momento.

\footnotetext{
${ }^{1}$ Doutor em Letras pela Universidade Federal do Paraná (UTFPR), professor-adjunto da Universidade Tecnológica Federal do Paraná (UTFPR), Câmpus Curitiba, Brasil.
} 
Se a peça de Guarnieri inaugurou a tradição brasileira do teatro engajado, que mais tarde foi sufocado pelo regime militar, um outro texto faz o balanço dessa geração. Tratase de Rasga Coração, última peça de Oduvaldo Vianna Filho, escrita entre 1972 e 1974. Durante o período em que elaborava o texto, o autor descobriu que estava com câncer. Foi nessa época que Vianinha fez, por meio de artigos e entrevistas, análises de sua trajetória e do percurso do teatro engajado no Brasil, bem como os resultados práticos obtidos por essa militância.

É sintomático o fato de que a resolução das duas peças se dê em cenas parecidas, em que o filho e o pai se confrontam. Além de abordar a diferença natural entre as gerações, ambas apontam para tratamentos diferenciados do componente ético. Enquanto Guarnieri mostra um Otávio bonachão mas irredutível, o Manguari de Vianinha é uma personagem multifacetada, que faz uma reavaliação intensa de suas convicções políticas e de sua vida.

O objetivo deste artigo é fazer uma comparação entre as duas peças, tendo como um dos principais pontos de vista a cena em que pai e filho se confrontam. A partir da análise dos binômios Manguari-Luca, Otávio-Tião, pretendemos ver como se dão os posicionamentos éticos de Otávio e de Manguari. Em seguida, partiremos da ideia de que Eles Não Usam Black-Tie é o começo do percurso do teatro engajado no Brasil e Rasga Coração, o encerramento desse ciclo. Assim, iremos verificar as diferentes concepções defendidas nas duas peças quanto ao engajamento político.

Na primeira parte do trabalho, será analisada a peça Eles não Usam Black-Tie a partir de cena em que Otávio expulsa Tião de casa. Na sequência, procuraremos definir o conceito de engajamento político e ético que o texto sugere. Depois, os mesmos procedimentos serão adotados para a leitura de Rasga Coração. Por fim, no fechamento será feita a comparação entre as duas peças.

\section{Análise de Eles não usam...}

Escrita em 1955 e encenada em 1958 pelo Teatro de Arena, Eles não usam Black-Tie foi gerada em meio a uma época de relativa democracia e otimismo, entre o fim do segundo governo Vargas e o golpe militar de 1964. Esse intermezzo democrático foi marcado pelo governo Juscelino Kubitschek e pela emergência de movimentos populares. A peça narra a história de uma família operária, de um morro carioca, no meio de uma greve; mostra a oposição 
entre dois universos: o da favela, ponto mais elevado, e o da cidade, considerada como um meio hostil e ameaçador. O ponto de vista da peça é o da favela. Tomamos contato com a oposição favela $x$ cidade mais por causa da ausência desta: a cidade só existe no imaginário das personagens.

Guarnieri faz uma pintura idealizada da vida na favela: seus habitantes são alegres e vivem em harmonia, existe um forte senso de cooperação que une as pessoas: a solidariedade se transforma em compromisso político e ético. As noções de coletividade, de classe e de respeito mútuo imperam. Elas são tão fortes que burlar o código, a ética local, significa trair e não ser mais aceito pelo grupo. Em contraponto, a cidade representa a falta de solidariedade, o individualismo, a concorrência desleal; é uma ameaça à ordem e à tranquilidade da favela.

A personagem do pai, Otávio, simboliza a comunidade. Ele é ao mesmo tempo uma pessoa bem-humorada e com um grande senso de solidariedade. É um dos organizadores da greve. Suas aspirações são modestas: deseja apenas que a metalúrgica dê aumento aos trabalhadores. Otávio não tem a intenção de se aburguesar e deixar seu meio social. Já filho Tião tem uma história diferente da vivida pelas outras personagens da favela. Quando criança, foi criado por um casal de padrinhos na cidade. Tião acredita que a greve não vai resolver a situação dos trabalhadores. Para ele, o movimento não traz a mudança que lhe possibilitará a ascensão social e a volta para a cidade onde, acredita, terá melhores condições de vida.

A greve é um elemento importante na peça. É através dela que se acirram as diferenças entre o pai, organizador, e o filho, fura-greve. No texto, só sabemos o posicionamento de Tião em relação à greve no segundo ato, no diálogo com Jesuíno, que tenta convencê-lo a furar o movimento para ser beneficiado pelas chefias da metalúrgica, de maneira velada. No entanto, Tião prefere assumir, diante da comunidade, sua opção por não aderir à paralisação. A falta de caráter de Jesuíno põe em evidência a honestidade de Tião. Se por um lado ele fura a greve, não o faz sem estar amparado numa justificativa plausível.

Eles Não Usam Black-Tie apresenta convenção teatral realista. A peça traz elementos novos para a dramaturgia brasileira (CAMPOS, 1988, p. 42). O primeiro deles é a temática. Foi a primeira vez que uma peça brasileira tratou de uma greve a partir do ponto de vista popular. Outra característica importante é a simplicidade da estrutura e sua linguagem coloquial bem marcada. Black-Tie se passa em cerca de dez dias. É o tempo 
necessário para estourar a greve e o tempo que leva para acontecer o noivado de Tião e Maria. A história é contada em ordem cronológica, de forma quase didática: o primeiro ato apresenta as personagens; o segundo expõe as dúvidas e aspirações de Tião, o terceiro apresenta as consequências das ações de Tião. A peça se concentra sobre o tempo presente de um ponto de vista objetivo, mostrando apenas a exterioridade das personagens.

O terceiro ato de Back-Tie mostra a exposição do problema ético entre pai e filho. No início do ato, Tião toma café antes para ir à fábrica sozinho, sem a companhia do pai. Logo depois da saída do filho, Otávio toma café e fala com Romana sobre a greve. Romana percebe a intenção de Tião em furar a greve e o perigo que Otávio poderá correr, nos piquetes. Com a saída dos dois, Romana começa a ler cartas, para adivinhar o futuro. As cartas dão as pistas para a prisão do marido e a traição do filho. Maria é o próximo interlocutor de Romana. Vem lhe contar da gravidez e falar do amor que sente por Tião. O clima é de quase relaxamento. No entanto, chega Bráulio com duas notícias: a da traição de Tião, que furou a greve com outros 17 funcionários, e a da prisão de Otávio. Tião explica que não foi covarde e confirma seu ponto de vista a Maria:

Tião - Não te preocupa, Maria. O que interessa pra gente é que eu não vou perdê o emprego. Eu entrei, furei a greve, o encarregado tomou nota do nome da gente. Deu mil cruzeiros pra cada um de gratificação e disse que a gente não ia arrependê. Pra mim é o que basta (GUARNIERI, 1966, p. 48).

Esta fala deixa claro seu posicionamento: não queria sacrificar o próprio emprego por uma briga da categoria. Sendo assim, acreditava que agiu de forma ética, de acordo com as própria convicções. Tião percebe claramente que sua conduta é regida pela lógica do capitalismo, comum na sociedade da cidade, embora viva na favela, onde impera a cooperação. Ele está consciente de que não seria mais aceito por aquela sociedade, já que cometeu o pior pecado possível, que é contrariar o princípio da cooperação.

Em seguida, chega Otávio, que foi preso pela DOPS por comandar a greve na frente da fábrica. A conversa entre ele e Tião traz a discussão ética para dentro do seio familiar. É o ponto alto da peça:

[Cena 3, Quadro 2. Otávio chega à casa, depois de sair da delegacia. É recebido como herói. Em seguida, Tião pede para falar com o pai. Ficam a sós e começam a conversar]

[...] Otávio - Bem, pode falá.

Tião - Papai ...

Otávio - Me desculpe, mas seu pai ainda não chegou. Ele deixou um recado comigo, mandou dizê pra você que ficou muito admirado, que se enganou. $\mathrm{E}$ pediu pra você tomá outro rumo, porque essa não é casa de fura-greve! Tião - Eu vinha me despedir e dizer só uma coisa - não foi por covardia! Otávio - Seu pai me falou sobre isso. Ele também procurou acreditá que num 
foi por covardia. Ele acha que você até teve peito. Furou a greve e disse para todo mundo [...] Ele acha, o seu pai, que você é ainda mais filho da mãe! Que você é um traidô dos seus companheiro e da sua classe, mas um traidô que pensa que tá certo! [...]

Tião - Eu queria que o senhor desse um recado a meu pai ...

Otávio - Vá dizendo.

Tião - Que o filho dele não é um "filho da mãe". Que o filho dele gosta de sua gente, mas que o filho dele tinha um problema e quis resolvê esse problema de maneira mais segura. [...]

Otávio - (perdendo o controle) Se eu te tivesse educado mais firme, se te tivesse mostrado melhor o que é a vida, tu não pensaria em não ter confiança na tua gente...

Tião - Meu pai não tem culpa. Ele fez o que devia. O problema é que eu não podia arriscá nada. Preferi tê o desprezo de meu pessoal pra poder querer bem, como eu quero querer, a tá arriscando a vê minha mulhé sofrê como minha mãe sofre.

$[\ldots]$

Otávio - (dirigindo-se aos quarto dos fundos) Tua mãe, talvez, vai querê falá contigo ... Até um dia! (Tião pega uma sacola que deve estar debaixo de um móvel e coloca seus objetos. Camisa que estão entre as trouxas de roupa, escova de dentes, etc.).

Sem dúvida essa é a cena mais incisiva da peça, por concentrar a discussão do tema mais importante, a ética. Alguns elementos colaboram para que isso aconteça. Por exemplo, o silêncio. Existe um contraste com a situação anterior, em que praticamente todas as personagens receberam com alegria e barulho a chegada de Otávio. Até mesmo Otávio, com suas brincadeiras, nunca esteve tão sorridente e barulhento em toda a peça. Em contraste, a cena da conversa entre o pai e o filho se dá em ambiente de silêncio: as pessoas esvaziam o cômodo, a atmosfera de festa é trocada por um clima grave.

No diálogo de Tião e Otávio, Guarnieri cria um recurso que permite a distinção, em Otávio, entre o pai e o político. Otávio refere-se a si mesmo em terceira pessoa. Esse procedimento provoca, na verdade, um distanciamento que garante a decisão de Otávio. Ao excluir o pai do julgamento, o Otávio político faz pender a balança para o lado da comunidade e das diferenças de valores que existem entre ele e Tião. No entanto, Guarnieri mostra que o pai, que tenta forjar uma certa serenidade, assume a primeira pessoa nos momentos em que o diálogo se toma mais crítico.

A atitude ética de Otávio remete necessariamente a um procedimento que privilegia a questão política acima do interesse pessoal. O endurecimento ético de Eles não Usam Black-Tie aponta para uma leitura única, que considera o posicionamento do pai como o mais correto. Embora Tião não seja um traidor de suas próprias convicções, traiu sua classe por pensar diferente. No Brasil dos anos JK, uma questão parecia ser mais importante: informar ao povo que ele estava sendo explorado e que precisava agir com 
REVISTA LETRAS - ISSN 2179-5282 - v.16, n. 19, jul./dez. 2014 - UTFPR - CURITIBA

http://periodicos.utfpr.edu.br/rl

firmeza, elevando a discussão política.

\section{Um olhar sobre Rasga Coração}

Rasga Coração é uma espécie de testamento da obra de Oduvaldo Vianna Filho pelo fato de ter sido seu último texto. Parece que Vianinha tinha claro que se tratava de um testamento, já que escreveu um prefácio explicando as razões do texto e dicas para a leitura. Ele procurou deixar claro os procedimentos de que se valeu na construção do texto, desde a temática até mesmo as convenções teatrais utilizadas. Conforme Vianinha escreve, Rasga Coração é uma homenagem "ao lutador anônimo político, aos campeões das lutas populares; preito de gratidão à 'Velha Guarda', à geração que me antecedeu, que foi a que politizou em profundidade a consciência do país" (VIANNA, 1980, p. 13).

Esse lutador pode ser identificado com o pai de Vianinha, Oduvaldo Vianna, artista de esquerda perseguido no período do Estado Novo de Getúlio Vargas. O revolucionário Manguari Pistolão do texto pode ser lido também como um alter ego do próprio Vianinha. Conforme o prefácio, o segundo tema da peça são "as diferenças que existem entre o 'novo' e o 'revolucionário'. O 'revolucionário' nem sempre é novo absolutamente e o novo nem sempre é revolucionário" (p. 13). Isso deixa patente que, na luta entre gerações que existe na peça, Vianinha está do lado do pai, sendo dele a voz da razão: "No final, no frigir dos ovos, o revolucionário para mim, o novo é o velho Manguari. Revolucionário seria a luta contra o cotidiano, feita de cotidiano" (p. 13).

Em seguida, Vianinha aponta para as convenções teatrais que utiliza para a realização de Rasga Coração: “A peça conta uma história, com todos os mecanismos do playwright: aproximação psicológica, crescendo de tensão, etc. Ao mesmo tempo, a peça apresenta dados, remonta momentos históricos, etc., utilizando a técnica da 'colagem' que usamos em Opinião e outros espetáculos" (p. 13). Com esses dados, prepara o leitor para uma observação guiada. A ideia é sempre pender para o lado do pai, como acontece em Eles Não Usam Black-Tie.

No entanto, em Rasga Coração, a concepção do que é revolucionário é diferente. Na peça de Guarnieri, a personagem de Otávio é apresentada em função de uma estrutura de pensamento político. Ele não faz nenhuma releitura profunda de sua trajetória. Manguari, por outro lado, está em crise constante e é ele quem procura se adequar ao ponto de vista "novo" e "revolucionário" do filho. Em comum, as duas peças têm o 
desfecho, em que pai e filho se encontram para discutir a divergência de suas concepções políticas.

Rasga Coração conta a história do funcionário público e ativista de esquerda Custódio Manhães Jr., o Managuari Pistolão, 57 anos, que se defronta, no plano ideológico, com o filho hippie Luís Carlos, o Luca, 17 anos. A peça mostra a tentativa de compreensão da parte de Manguari, em momento privilegiado. Ou seja, a oposição pai $x$ filho desencadeia no pai uma crise que lhe obriga passar a limpo toda sua trajetória de vida e, a partir de seu ponto de vista, a história recente do país.

O primeiro elemento formal que chama a atenção em Rasga Coração é a utilização de dois planos narrativos diferenciados - o que não existe na simplicidade da estrutura de Black-Tie. Os planos da memória e da realidade propiciam o aprofundamento psicológico de Manguari Pistolão. Os fantasmas que aparecem na memória de Manguari, tais como 666, Castro Cott, Camargo Velho e Lorde Bundinha, servem para moldá-lo como personagem e lhe acentuam as contradições. Junto à categoria psicológica, Vianinha consegue juntar a abordagem histórica. No plano da memória, Manguari repassa toda sua trajetória de ativista político. Junto a ela, faz uma releitura da história do Brasil.

O segundo e último ato de Rasga Coração mostra a inserção do problema da ética a partir da relação pai $x$ filho. É nessa altura da peça que Manguari tenta se aproximar do filho, querendo fazer com que ele "abra os olhos" para a participação política e o engajamento pela causa da esquerda. O pai, no entanto, faz concessões aos erros do filho. E a partir da tentativa de encontrar algo em comum, do ponto de vista ideológico, que se dá todo o processo de revisão que Manguari faz de seus próprios postulados políticos.

O segundo ato mostra o engajamento do pai numa causa política do filho. Luca é proibido de entrar na escola porque usa cabelo comprido e calça jeans. Para Manguari, a proibição é absurda e ao mesmo tempo a chance do filho lutar por uma causa, mobilizando todos os pais. Manguari acredita que o problema do filho é só a proibição do colégio. Mas é através de leituras diferentes do mesmo fato que a peça mostra as diferenças ideológicas entre os dois. Num certo ponto, Manguari elabora um plano de ação para o filho, a fim de derrubar a proibição da escola. Esse plano inclui a reivindicação de direitos conquistados, da forma mais legalista possível. Ele sugere ao filho a visita a órgãos de respaldo jurídico como a Ordem dos Advogados do Brasil, a Academia Brasileira de Letras.

Esse tipo de estratégia não agrada ao filho, que acredita que a questão não deve ser resolvida do ponto de vista das instituições, já que é contra as instituições. Uma fala de 
Luca sintetiza as diferenças ideológica dos dois:

Luca - Mas eu não quero dizer - "querem cortar o meu cabelo" - é muito mais que isso! Muito mais que isso eu quero super-denunciar, saca? "Querem cortar a minha vida", mas isso eu vou dizer aonde, super? Entrevista com o Secretário da Educação? Câmara dos Deputados? Com todos os donos de colégios? Como é, o tal Conselho Nacional de Cultura, como é a lista? (VIANNA, 1980, p. 61).

Para Luca, o pai não tinha nada de revolucionário. A atividade política era apenas um desvio de um problema maior, que era não gostar da própria vida:

Luca - Mas a experiência é pra isso? Não quero, não quero ficar experimentado! Você é que é revolucionário, então! O mesmo ônibus 415, com trocado no bolso que não gosta de brigar com o trocador, o editorial, leu o editorial? Conversou com o jornaleiro, atravessou a rua no sinal, na faixa 25 anos, ônibus 415 com trocado no bolso, 25 anos assinando ponto em repartição, reuniões quarta-feiras, mês de finanças, rifas para passar, recorte de jornal no bolso "leu o artigo do Tristão?" ônibus 415, o meu revolucionário de 415 de trocado no bolso, terno, gravata, 25 anos assinando ponto? Mas é isso a experiência? Esse silêncio por dentro, que fica dentro de você? Experiência, é desistir de ser feliz? Ação direta! Ação direta! Ação direta! (Luz) (p. 62).

A seguir, reproduzimos trechos das cenas 9 e 10, em que Manguari expulsa

Luca de casa. Na sequência, faremos uma leitura do texto a partir do componente ético:

Cena 9

(A luz abre brilhante sobre Camargo Moço e Nena)

$[\ldots]$

Manguari - ... E ele ofereceu o colégio dos dominicanos para vocês fazerem recuperação em dezembro, e, se você passar, ele diz que dá o diploma do científico para vocês poderem fazer o vestibular, Luca. Não é sensacional? [...] A solidariedade, filho ... Afinal deu algum resultado o movimento que você fez, Luca ... (Silêncio) Não é uma maravilha fazer vestibular ainda?

Luca - (Silêncio) ... Vestibular é uma palavra engraçada ... ela não diz o que é a coisa ... vocês não têm cuidados com as palavras ...

Manguari - ... Que foi, Luca?

Nena - ... Não está contente, filho? [...]

Luca - (Silêncio) Ih, pai ... ih, Custódio ... você vai ficar muito zangado ... (Pára)

Manguari - ... Que foi, Luca?

Luca - ... (Longo Silêncio) ... Ih, não vou fazer vestibular não ... não vou para colégio de Frei ...

Manguari - ... O que é? Por que? Mas o que é isso?

Nena - .. Não fala assim, filho ...

$[\ldots]$

Manguari - ... Está certo, Luís Carlos, está certo, eu não discuto mais! Você faz como quiser, faz como decidir, tem todo o meu respeito, mas agora é fora da minha casa, menino, entendeu? (Luz acende sobre 666)

666 - ... Fora da minha casa com a Michela!

Manguari - ... Aqui você não fica mais, não pago mais trigo sarraceno, não pago roupa, pasta de dente, não sou pensão!. ..

Luca - ... Puxa, pai, que é isso?

Manguari - ... É isso, é isso, é isso ...

Luca - Não tenho onde ir, pai, vou pra onde? 
666 - Vai nos churrascos cívicos, come nos churrascos cívicos!

Nena - Por favor ... Custo!. ..

Manguari - ... Não posso mais, não posso mais viver com uma pessoa que me olha como se eu estivesse morto! [...]

Luca - Você é que pensa que é revolucionário, é a doce imagem que você faz de você, pai, mas você é um funcionário público, você trabalha para o governo! Para o governo! [...]

Nena - Custo, meu Deus do Céu, Custo, pelo amor de Deus ... (Luz reabre sobre 666 e Lorde Bundinha enquanto prossegue o entrevo)

666 - Fora! Fora da minha casa com a Michela!

Lorde Bundinha - ... Você disse pra ele que agora fabricamos penicose mesmo assim ele te mandou embora? Que falta de compreensão ...

Manguari - (Desiste do corpo-a-corpo) ... Está bem, Nena, vamos embora, Nena. Vamos embora. (Sai. Nena fica um pouco atrás. Ficam só Camargo Moço e Luca. Tempo de Silêncio)

Camargo Moço - ... Ih, amigo, ih. .. se eu soubesse que ia acontecer isso, eu nem vinha aqui ... pô, desculpe ... acho que devia ter falado com você linha direta.

Luca - (Ainda está muito abalado mas mantém-se) - não tem problema, amigo, sem problema sabe como é que chamavam os cristãos no Império Romano? "Gente esquisita e intratável os bárbaros do interior do Império ..." hoje todo mundo se benze ... eu sei que é isso que vou enfrentar ... meu pai tem que descarregar em alguém ele ter vivido sem ter deixado marca de sua presença ...

Camargo Moço - Ô Luca, ô Luca, não é isso não, teu pai não deixou marca? Mas cada vez que começa uma assembleia num sindicato, a luz baça, teu pai está lá, cada chapéu na mão, entra na Justiça do Trabalho, teu pai está lá, cada vez que, em vez de dizer países essencialmente agrícolas, dizem países subdesenvolvidos, teu pai está lá, cada vez que dizem imperialismo, em vez de países altamente industrializados, teu pai está lá, cada vez que fecham um barril de petróleo na Bahia, teu pai está lá ... teu pai é um revolucionário, sim ...

Luca - ... Petróleo, quilovates, toneladas de aço, megatons, você também só consegue entender o mundo nesses termos não é, companheiro? ... o assalto à natureza ... olha, muita facilidade no vestibular (Tempo de silêncio)

Camargo Moço - ... Mais uma vez

desculpe ... tchau ...

Luca - ... tchau ... (Luz desce lenta

sobre eles)

Cena 10

(Abre sobre Manguari. Faz um relatório concentrado. Nena aflita, olhos estourados de chorar. Anda de um lado para o outro. Um tempo, ela não aguenta)

[...]

Manguari - é assunto realmente encerrado, Nena.

Nena - ... Estou com falta de ar, Custo, por favor, como é que eu vou ficar os dias nesse apartamento sem o Luís Carlos, sem a roupa dele, a comida, remédios, Custo, por favor ...

Manguari - ... Você encontra ele quando quiser Nena, onde quiser, mas aqui ele (Luca aparece. Mochila nas costas. Silêncio, longo tempo de silêncio).

Luca - ... Bom ... estou de saída (Silêncio. Vai até Nena) Até logo, mãe ... (Nena se abraça nele. Chora contida. Luca meio chora) a gente se vê, está bem? Nena - ... Está bem, filho, está bem ...

Luca - (silêncio) - tchau, pai ... (Manguari quieto. Luca vai até ele lento. Beija a face de Manguari. Tempo) Tchau

Manguari - ... Até logo, Luís Carlos... (Um tempo. Luca sai. Nena desaba numa poltrona chorando quieta. Manguari absolutamente imóvel).

$[\ldots]$ 


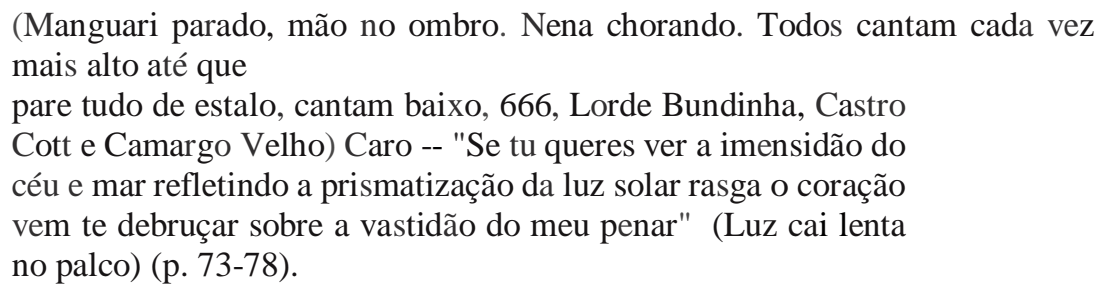

As duas cenas que foram transcritas acima (9 e 10) são as mais importantes de Rasga Coração por apresentarem a resolução da peça. É aqui que toda a incursão de Manguari ao ponto de vista ideológico de Luca, buscando pontos de contato, termina. $\mathrm{O}$ primeiro elemento que chama a atenção na peça é a forma abrupta com que Manguari toma a decisão de mandar o filho embora. Durante todo o texto ele é caracterizado como uma pessoa extremamente tolerante com o filho. Para ressaltar a forma incisiva da decisão, a cena se dá na presença de Camargo Moço e Nena, de forma agressiva.

Logo depois que Luca trata o pai com desrespeito, recebe um tapa no rosto. A decisão de Manguari se deu de forma repentina porque chegou um momento que viu que a intolerância do filho chegou ao limite e não tinha mais volta. Disse ele: "não posso mais viver com uma pessoa que me olha como se eu estivesse morto". Em seguida, Luca continua argumentando que o pai apenas "pensa que é revolucionário", mas é apenas "um funcionário público, que trabalha para o governo". A cena põe em questão todo o problema ético posto em questão pela peça na figura de Manguari Pistolão. Como já foi observado, trata-se de uma personagem bastante humanizada - e para isso colabora a escolha que Vianinha fez do plano dá memória a partir do fluxo de consciência de Manguari, através do qual podemos perceber seu estado psicológico. Seu lado humano consegue suplantar o político. Impera em si uma grande tolerância que não existe, evidentemente, em Otávio de Eles não usam Black- Tie.

Quando expulsa o filho de casa, fica patente que a decisão é do pai, e não do político. O seu embate é direto. Manguari expulsa Luca porque entre os dois existe uma diferença crucial. O pai é tolerante e democrático, capaz de agir de forma antiética para salvar o filho. Luca é completamente intolerante. Não são necessariamente suas ideias que fizeram seu pai mandá-lo embora, mas a incapacidade de diálogo. De forma geral, pode-se dizer que existe um senso ético em Manguari Pistolão que pende muito mais para a questão familiar e humana, e não apenas para o problema político e ideológico.

Que significado teria Rasga Coração, tomada como metáfora da trajetória de um 
teatro político, que se iniciou com Black-Tie? Entre muitas leituras possíveis, apostamos na seguinte. A peça de Vianinha, de grande elaboração formal, parece um corpo estranho dentro de uma tradição comprometida com a veiculação de ideias políticas. No lugar da simplicidade formal e da transparência no significado de Black-Tie, por exemplo, a peça de Vianinha é elaborada de um ponto de vista bastante complexo. Além disso, o herói Manguari Pistolão deve ser visto muito mais pelas suas qualidades humanas do que propriamente políticas. Não é um modelo a ser seguido, como o Otávio de Black-Tie. Dessa forma, Rasga Coração pode ser entendida como uma crítica ao maniqueísmo e ao excesso de preocupação com o elemento político, em detrimento do estético.

\section{Considerações finais}

Para concluir esse trabalho, retomamos as duas perguntas iniciais: a) que diferença existe no tratamento do componente ético nos binômios Manguari-Luca e Otávio- Tião?; b) levando em conta que Black-tie é o início e Rasga Coração, o fechamento de um ciclo de dramaturgia política no Brasil, quais são as mensagens que cada uma dessas peças transmitem dentro do contexto desse teatro engajado?

A primeira pergunta já foi respondida ao longo do texto. Em Black-Tie existe um posicionamento ético exemplar, em que prevalece o elemento político sobre o indivíduo. Reforçam essa ideia as convenções teatrais realistas adotadas na peça. Numa perspectiva mais ampla, o ato de Otávio faz lembrar a pintura de Jacques Louis David (1748-1825), especificamente o quadro "Os lictores trazem a Brutus os corpos de seus filhos". A tela mostra, a partir da esquerda: os filhos sendo trazidos pelos algozes, ao fundo, sob luz forte; o pai sentado, com o rosto sereno em primeiro plano, na penumbra; e três mulheres (possivelmente a mãe e duas filhas) aos prantos, sob forte iluminação. Brutus mandou matar os filhos porque estes traíram a república romana. 


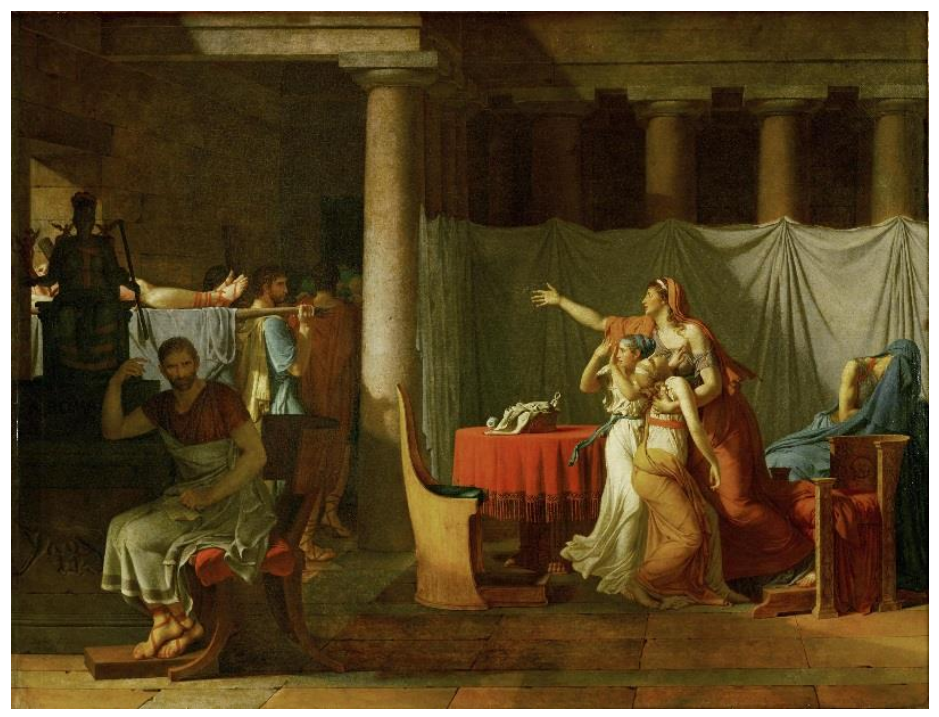

Essa pintura, exposta no Salão de 1789, após o triunfo da Revolução Francesa, é um dos emblemas da Revolução. Logo depois da queda da Bastilha, era preciso um endurecimento ético para que a nova ordem fosse mantida. David retratava em seus quadros a postura de heróis que agiam contra a vontade de suas famílias para satisfazer uma necessidade política. Em quadros como "Os lictores", "O Juramento dos Horácios" e "A Morte de Sócrates", a personagem central sempre toma uma decisão respeitando a ética política, sufocando, do outro lado, a questão familiar. Nos quadros, a família é sempre representada por mulheres, que aparecem chorando diante das decisões de seus maridos.

Situação paralela pode ser encontrada na última cena de Eles Não Usam Blacktie, em que o pai expulsa o filho, demonstrando uma postura ética em relação ao código da comunidade da favela. Romana, que representa o lado humano, é quem termina a peça, catando feijão e chorando - evocando as mulheres de David. Em Rasga Coração o problema é diferente. A peça mostra também, na cena final, um pai que expulsa o filho de casa. Mas o que está em jogo não é a questão política. Manguari Pistolão é caracterizado na peça - e as convenções teatrais de Rasga Coração põem em relevo essa ideia - como uma personagem demasiado humanizada para fazer pender a balança apenas para a política. O filho Luca é despejado de casa porque não respeita o pai, por ser intolerante, e nunca por ter traído as convicções de Manguari.

Qual seria a resposta para a segunda pergunta? O herói Otávio encontra seu correspondente em Brutus, de David. O início do percurso do teatro brasileiro engajado é muito bem marcado por um herói que não se rende ao nepotismo e à decisão 
influenciada pelo ambiente familiar. Ele prefere "matar" o filho a tê-lo em casa como traidor do ideário da comunidade em que vive. Otávio olha para frente, ao lado de sua comunidade.

Já em Rasga Coração, parece haver uma crítica ao herói ético desenhado por Guarnieri e por todo o teatro engajado brasileiro. Manguari Pistolão não corresponde a um modelo a ser seguido pela esquerda brasileira. O embate ideológico com o filho desencadeia no pai um fluxo de consciência em que este faz a arqueologia de suas ideias políticas. Na exposição dos fantasmas de Manguari, nota-se m indivíduo muito mais dividido e frustrado, que não acredita na perspectiva otimista da revolução.

Escrita numa época em que Vianinha tinha uma visão bastante crítica sobre a atuação do teatro engajado no Brasil, Rasga Coração pode ser entendida como o fim de um percurso, de um olhar para trás não muito confortável, reafirmando, através de sua elaboração esmerada, a necessidade do constante conluio entre a estética e a política na realização do espetáculo teatral.

\section{Referências}

CAMPOS, Cláudia de Arruda. Zumbi, Tiradentes. São Paulo: Perspectiva, 1988.

GUARNIERI, Gianfrancesco. Eles não usam Black-Tie. São Paulo: Brasiliense, 1966. PRADO, Décio de Almeida. Peças, Pessoas, Personagens: o teatro brasileiro de Procópio Ferreira a Cacilda Becker. São Paulo: Companhia das Letras, 1993.

VIANNA FILHO, Oduvaldo. Rasga Coração. Rio de Janeiro: Serviço Nacional do Teatro, 1980. 